\title{
ANTIFERTILITY EFFECT OF AN INTRA-UTERINE SILK THREAD SUTURE IN RATS WITH A CONNECTION BETWEEN THE TWO UTERINE HORNS
}

\author{
S. K. BATTA AND R. R. GHAUDHURY \\ Department of Pharmacology, Postgraduate Institute of Medical Education and Research, \\ Chandigarh, India
}

(Received 1st August 1967, accepted 27th November 1967)

\begin{abstract}
Summary. In rats provided with a surgically created anastomosis between the two uterine horns and subsequently mated, implantation occurs with great regularity. Implantation sites were seen in twentysix out of the thirty-two rats examined at laparotomy on Day 10 of pregnancy.

In rats with such an anastomosis and unilaterally ovariectomized, implantation occurred in both uterine horns. There was evidence of implantation in nine out of twelve rats in the left uterine horn, even though the left ovary had been removed, indicating that the anastomosis was patent.

Out of fifteen successfully mated rats with a connection between the two uterine horns and a silk suture in the lumen of the left uterine horn, only one rat showed evidence of implantation in the left uterine horn on Day 10 of pregnancy. There were no signs of implantation sites in the right horn in any animal in this series. The results demonstrated inhibition of implantation in the control horn when an intra-uterine device was placed in the experimental horn in rats with an anastomosis between the two horns. This suggests that the presence of a device in one horn led to the liberation of a substance which passed to the control horn through the surgically created anastomosis and there prevented implantation.
\end{abstract}

\section{INTRODUGTION}

It has been unequivocally demonstrated that a silk thread suture in one horn of the rat uterus prevents implantation after successful mating in that horn while normal implantation occurs in the contralateral horn (Doyle \& Margolis, 1963, 1964; Chaudhury, 1964; Chaudhury \& Tarak, 1965; Marston \& Chang, 1964). In mice, however, Doyle \& Margolis (1966) observed a significantly reduced number of implantations in the control horn when an intra-uterine foreign body (IUFB) had been introduced into the other horn. There is a small communication between the two uterine horns in this species, the connection appearing to be mainly in the upper part of the cervix. When injected into one 
horn passage of dye from that horn to the other has been demonstrated by Doyle \& Margolis (1966). They suggested that some inimical products might be formed in the lumen of the uterine horn in the presence of the device, which, having passed through the communication, could adversely affect implantation in the control horn. Ledger, Virkar \& Irwin (1966) also suggested that a silk thread suture introduced into the lumen of the rabbit uterus may produce a substance hostile to normal implantation.

If the intra-uterine device produces such a substance also in the rat a silk suture in one horn of the rat uterus should inhibit implantation in the contralateral control horn if an artificial communication or a fistula is created between the two horns. This would enable this substance to travel to the horn without the silk thread suture and prevent implantation. This possibility has been investigated by surgically creating such an anastomosis in adult fertile female rats. The first series of experiments was performed to determine whether a successful pregnancy would occur in animals subjected to the operative trauma involved in creating the anastomosis. The second series of experiments was performed to see whether fertilized ova from one horn could pass through the anastomosis into the other. The third series of experiments was performed to study whether the presence of an intra-uterine silk thread suture in one horn of the uterus would, in rats with an anastomosis between the two horns, prevent implantation in the control horn without the suture.

\section{METHODS}

The operation connecting the two uterine horns was carried out in the following manner. Adult fertile female rats weighing from 175 to $225 \mathrm{~g}$ were operated on when in oestrus. Under ether anaesthesia the abdominal cavity was opened and the antimesometrial surfaces of the two uterine horns apposed and sutured with chromic catgut 000 making the anastomosis complete. The different stages of the operation and the final appearance of both the uterine horns of the rat are shown in Text-fig. 1. The rats were allowed to recover from the anaesthesia, and
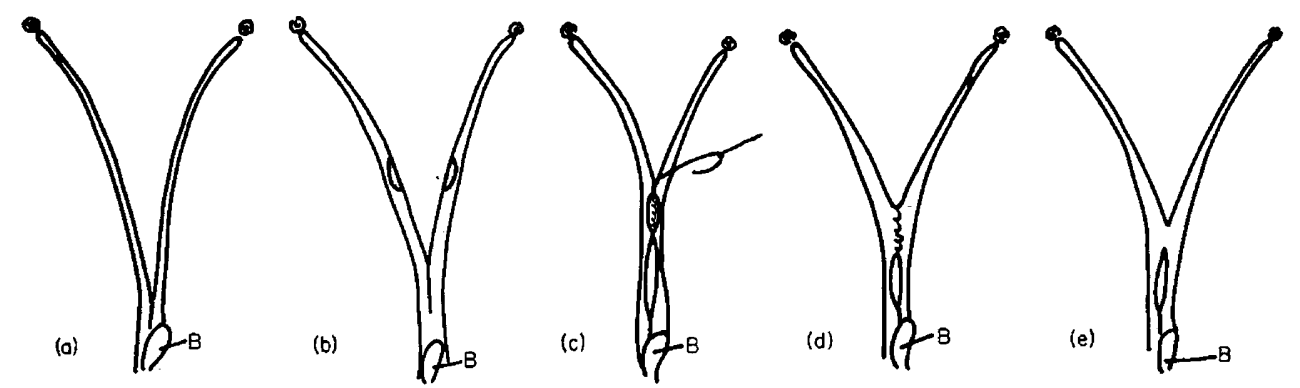

TEXT-FIG. 1. (a-e) Stages of operation producing a connection between the two horns of the rat uterus. $\mathrm{B}=$ bladder.

tetracycline (6 mg i.p.) was administered to them for 3 days after the operation.

In the second group of rats, unilateral ovariectomy was performed on the left side at the time of operation.

In the third group of animals, an intra-uterine silk thread suture was inserted 
into the lumen of the left horn of the uterus above the anastomosis during the operation.

After a rest of 14 days all the rats were placed for mating with proven fertile males and the vaginal smears examined daily. Presence of clumps of spermatozoa in the smear indicated successful mating and was termed Day 1 of pregnancy. Those rats which did not show evidence of spermatozoa in the vaginal smear for 30 days were discarded. The pregnant rats were killed on Day 10 and the number of implantation sites noted. The sites of implantations, whether in the left or right uterine horn or in the area connecting both horns, were also noted.

\section{RESULTS}

Table 1 lists the results of the first series of experiments in which thirty-two rats with a connection between the two horns were successfully mated. Evidence of implantation was detected in twenty-six. In all, eighty-nine implantation

TABLE 1

NUMBER OF IMPLANTATION SITES IN RATS MATED AFTER CREATION OF AN ANASTOMOSIS BETWEEN THE TWO UTERINE HORNS

\begin{tabular}{|c|c|c|c|c|}
\hline \multirow{2}{*}{$\begin{array}{l}\text { Rat } \\
\text { no. }\end{array}$} & \multicolumn{3}{|c|}{$\begin{array}{c}\text { Implantation sites seen on Day } 10 \text { after } \\
\text { detection of spermatozoa }\end{array}$} & \multirow{2}{*}{$\begin{array}{l}\text { Total no. } \\
\text { of implantation } \\
\text { sites }\end{array}$} \\
\hline & Left horn & $\begin{array}{l}\text { Area of } \\
\text { connection }\end{array}$ & Right horn & \\
\hline $\begin{array}{r}1 \\
2 \\
3 \\
4 \\
5 \\
6 \\
7 \\
8 \\
9 \\
10 \\
11 \\
12 \\
13 \\
14 \\
15 \\
16 \\
17 \\
18 \\
19 \\
20 \\
21 \\
22 \\
23 \\
24 \\
25 \\
26 \\
27 \\
28 \\
29 \\
30 \\
31 \\
32\end{array}$ & $\begin{array}{l}2 \\
3 \\
2 \\
1 \\
2 \\
- \\
- \\
2 \\
1 \\
2 \\
3 \\
- \\
- \\
2 \\
2 \\
- \\
- \\
- \\
- \\
- \\
1 \\
2 \\
- \\
1 \\
2 \\
2 \\
- \\
2 \\
-\end{array}$ & $\begin{array}{l}\overline{2} \\
3 \\
- \\
\overline{1} \\
- \\
\overline{1} \\
\overline{1} \\
- \\
- \\
\overline{1} \\
\overline{1} \\
2 \\
\overline{2} \\
\overline{1} \\
\overline{2} \\
1 \\
- \\
- \\
\overline{2} \\
\overline{2} \\
\overline{1}\end{array}$ & $\begin{array}{l}2 \\
2 \\
2 \\
- \\
- \\
- \\
- \\
1 \\
- \\
2 \\
2 \\
- \\
- \\
2 \\
4 \\
- \\
- \\
- \\
- \\
- \\
1 \\
3 \\
- \\
1 \\
3 \\
4 \\
\overline{5} \\
- \\
- \\
- \\
2\end{array}$ & $\begin{array}{l}4 \\
4 \\
7 \\
7 \\
1 \\
2 \\
1\end{array}$ \\
\hline
\end{tabular}


sites were observed: thirty-four in the left horn, thirty-six in the right horn and nineteen in the area connecting the two uterine horns.

Table 2 shows the number of implantation sites in unilaterally ovariectomized rats mated after the creation of an anastomosis between the two uterine horns.

TABLE 2

NUMBER OF IMPLANTATION SITES IN RATS MATED

AFTER GREATION OF AN ANASTOMOSIS BETWEEN

THE TWO UTERINE HORNS AND OVARIECTOMIZED

ON THE LEFT SIDE

\begin{tabular}{r|c|c|c}
\hline \multirow{2}{*}{ Rat no. } & \multicolumn{3}{|c}{$\begin{array}{c}\text { Implantation sites on Day } 10 \text { after } \\
\text { detection of spermatozoa }\end{array}$} \\
\cline { 2 - 4 } & Left horn & $\begin{array}{c}\text { Area of } \\
\text { connection }\end{array}$ & Right horn \\
\hline 1 & 3 & 1 & 4 \\
2 & 4 & - & 2 \\
3 & 1 & - & 2 \\
4 & 1 & - & 1 \\
5 & - & 1 & 2 \\
6 & - & 1 & 3 \\
7 & 1 & - & - \\
8 & - & 1 & 2 \\
9 & 1 & - & 4 \\
10 & 1 & - & - \\
11 & 2 & & \\
12 & 2 & &
\end{tabular}

TABLE 3

NUMBER OF RATS WITH AN ANASTOMOSIS BETWEEN BOTH UTERINE HORNS WHICH SHOWED EVIDENCE OF IMPLANTATION

\begin{tabular}{|c|c|c|c|c|c|c|}
\hline $\begin{array}{c}\text { Experimental } \\
\text { series }\end{array}$ & $\begin{array}{c}\text { Experimental } \\
\text { details }\end{array}$ & $\begin{array}{l}\text { No. of } \\
\text { animals }\end{array}$ & $\begin{array}{c}\text { No. of } \\
\text { animals } \\
\text { showing } \\
\text { evidence of } \\
\text { implantation }\end{array}$ & $\begin{array}{c}\text { Implantation } \\
\text { sites in } \\
\text { left horn }\end{array}$ & $\begin{array}{l}\text { Implantation } \\
\text { sites in } \\
\text { right horn }\end{array}$ & $\begin{array}{l}\text { Implantation } \\
\text { sites in } \\
\text { area of } \\
\text { connection }\end{array}$ \\
\hline$I$ & $\begin{array}{l}\text { Control rats } \\
\text { with connection } \\
\text { between both } \\
\text { uterine horns }\end{array}$ & 32 & 26 & 34 & 36 & 19 \\
\hline II & $\begin{array}{l}\text { Rats with a } \\
\text { connection } \\
\text { between both } \\
\text { uterine horns } \\
\text { and ovariecto- } \\
\text { mized on left } \\
\text { side }\end{array}$ & 12 & 10 & 16 & 22 & 5 \\
\hline III & $\begin{array}{l}\text { Rats with a } \\
\text { connection } \\
\text { between both } \\
\text { uterine horns } \\
\text { and an intra- } \\
\text { uterine silk } \\
\text { suture in the } \\
\text { left horn }\end{array}$ & 15 & $1^{*}$ & $1^{*}$ & Nil & Nil \\
\hline
\end{tabular}

* The intra-uterine suture could not be found and had been lost. 
There were implantation sites in the left horn of the uterus in nine out of twelve rats, even though the left ovary had been removed. In eight of these nine rats there was evidence of implantation in the right uterine horn, while in the ninth there were two implantation sites in the right uterine horn but none in the left horn. The total numbers of implantation sites in the right and left uterine horns were twenty-two and sixteen, respectively. The difference is statistically significant, $P<0.05$. In two animals in this series no implantation sites were seen in either horn of the uterus.

The results of the third series of experiments, in which rats with an anastomosis between the two uterine horns and carrying an intra-uterine device in one horn were successfully mated, indicate that only one of fifteen such rats showed evidence of implantation sites in the left uterine horn. No suture was found in this horn when the animal was killed (Table 3 ). In all other animals there were no implantation sites in either the left or the right uterine horn or in the area connecting them.

\section{DISCUSSION}

The results obtained in the first series of experiments indicate that the trauma of surgery when creating the anastomosis between the two uterine horns does not prevent implantation after successful mating following 14 days rest. Twenty-six out of the thirty-two rats showed evidence of implantation on the 10 th day and the average number of implantation sites was 3.6 per rat. Although the number of implantation sites per rat, as well as the percentage of animals which became pregnant after detection of spermatozoa $(81.2 \%)$, was less than the normal figures in this laboratory, yet the results indicated that implantation could occur successfully in a large proportion of rats with such a connection. The second series of experiments was performed to see whether it would be possible for any fluid or pharmacological substance to travel from one uterine horn to the other through the anastomosis. The patency of the anastomosis was established by the fact that even though ovariectomy was performed on the left side there were implantation sites in nine out of twelve rats in the left uterine horn, indicating that blastocysts could migrate from one horn to the other across the artificial opening. Hence, if the presence of a device in one horn of the uterus gave rise to a pharmacological substance in that horn there would be no difficulty in the substance reaching the other uterine horn across the anastomosis. Similar experiments were performed by Krehbiel (1946) but he could not demonstrate migration of fertilized ova in rats unilaterally ovariectomized and with an anastomosis of the type created in the present study. It is possible that adhesion formation did not allow migration to take place in Krehbiel's experiments.

The results obtained in the final series of experiments showed unequivocally that an IUFB in one horn of the rat uterus could inhibit implantation in the contralateral control horn if there is a connection between the two uterine horns. These results provide evidence for the first time that a pharmacological or toxicological substance may be produced by an IUFB and that this substance may be inhibiting implantation. 
This might explain the experimental results obtained by Doyle \& Margolis (1966) in mice. The IUFB in one horn of the uterus could have released or produced a substance, which, travelling through the opening normally present between the two horns of the mouse uterus, prevented implantation in $70 \%$ of the animals in the control horn also. Such a possibility of a pharmacological or toxicological substance being formed by a foreign body in rabbits has also been mentioned by Ledger et al. (1966) although in the rabbit the two horns are entirely separate. Our results in rats, when taken in conjunction with the other work mentioned above, suggest that in at least three species, the mouse, rat and rabbit, this phenomenon of a pharmacological toxic substance inimical to normal implantation being produced by an IUFB is possible. It has been suggested that in the ferret, too, which has a small communication between the two uterine horns, an IUFB in one horn prevents implantation in the other horn (W.H.O., 1966).

Although the mechanism of action of the intra-uterine device in preventing pregnancy is not clearly understood, some suggestions have been made as a result of work done in various laboratories. The hypothesis regarding increased tubal motility may be mentioned first. Mastroianni \& Hongsanand (1964) demonstrated that in superovulated rhesus monkeys fitted with an IUFB the transport of ova through the Fallopian tube is accelerated. Acceleration of ovum transport, therefore, has been suggested as the mechanism whereby the IUFB may be speeding the passage of the ova through the tube to reach the uterus within a day or less instead of the usual 3 to $3 \frac{1}{2}$ days after ovulation. The fertilized ovum would reach the uterus in such an immature state that it would not be able to implant (cf. Margulies, 1962; Tietze, 1962). It must, however, be remembered that Mastroianni \& Hongsanand's investigations were performed under conditions such as superovulation and artificial insemination which do not occur normally.

In normal female monkeys, Kelly \& Marston (1967) demonstrated the presence of blastocysts and ova in the Fallopian tubes in the presence of an intra-uterine device. In monkeys without an IUFB blastocysts were recovered from the uterus from Day 11 to Day 18 of the cycle. This study, in which neither superovulation nor artificial insemination were employed, indicates that tubal passage of the ovum is not markedly hastened in the presence of a device. Consequently, the hypothesis that the IUFB exerts its antifertility effect by causing increased tubal motility does not appear to be tenable.

Bengtsson \& Moawad (1966) reported that, while insertion of an IUFB early in the human reproductive cycle resulted in no immediate change in myometrial activity, the uterine activity after the 19th day gradually increased and reached an activity characteristic of the pre-labour uterus. These authors suggest that this pre-labour-like activity evolves at a time which coincides with the time of implantation of the fertilized ovum. Marcus, Marcus \& Wilson (1966) also showed increased uterine motility in rats after introduction of an intra-uterine device. However, Johnson, Theodore \& Brewer (1966) could not confirm the findings of Bengtsson \& Moawad (1966), while Chaudhury (unpublished observations) has shown that the sensitivity to oxytocin of the rat uterus with an IUFB is not altered. 
The suggestion that, in rats, the IUFB exerts its antifertility activity by causing inflammation was made by Greenwald (1965). He suggested that the inflammatory reaction appeared to be essential for interruption of pregnancy. A similar suggestion has recently been made by Parr (personal communication) after his experiments on rats obtained and maintained in germ-free conditions. Jessen, Lane \& Greene (1963) and Israel \& Davis (1966) also feel that inflammation may play a part in the antifertility effect of the device in humans. Other investigators, however, have failed to detect any inflammatory reaction after introduction of a foreign body in the rat uterus (Kar, Kamboj, Goswami \& Chowdhury, 1965; Doyle \& Margolis, 1964; Sudha, Chakravarty \& Chaudhury, 1967). Mathur \& Chaudhury (1968) have recently demonstrated that the IUFB device increases the mast cell content in the uterus where it is placed. It is not yet known whether the increased mast cells are the result of inflammation or increased oestrogenicity or whether they may be playing a different role in the mechanism of action of the IUFB. In humans, Sujan \& Virick (1964), Bonney \& Cooper (1964), Morese, Peterson \& Allen (1966) and Rozin, Sacks \& Shenker (1967) found no evidence of inflammation induced by the IUFB.

The other mechanisms by which the intra-uterine device could act in humans, by inhibiting ovulation or blocking sperm migration, have been ruled out. Various investigators have shown that the IUFB does not inhibit ovulation or sperm migration in humans (Lippes, 1962; Sujan \& Virick, 1964; Hall, Sedlis \& Chabon, 1964; Malkani \& Sujan, 1964). It is only in ruminants such as cattle and sheep that the IUFB acts by inhibiting ovulation and by the prevention of sperm migration (Buch, Shukla \& Hawk, 1964; Hawk, Conley, Brinsfield \& Righter, 1964; Hawk, 1965; Ginther, Woody, Janakiraman \& Casida, 1966).

The results obtained in this investigation indicate that in addition to the two possibilities of increased tubal motility and inflammatory changes a third one of a pharmacologically active substance being produced by the IUFB must be considered. It is even possible that this substance could be produced as a result of inflammatory changes in the uterus or could be responsible for increased myometrial activity. This pharmacological substance should be searched for and the intraluminal secretions studied pharmacologically. This is being done in this laboratory and the substance appears to be a very potent smooth muscle contracting substance (unpublished observations). Kar (1964) has suggested that the IUFB could cause osmotic changes in the intraluminal fluid leading to dehydration of the blastocyst, while Marston \& Chang (1964) believe that a biochemical substance necessary for implantation may be exhausted by the device or that the device may produce a toxic substance which prevents development of the fertilized ovum. The results obtained in the present series of experiments indicate support for the latter hypothesis. It is felt that the IUFBs may exert the antifertility effect in several ways and it is not necessary that there should be a single mechanism of action.

\section{ACKNOWLEDGMENTS}

The authors are indebted to Mr Gurdev Singh Khandhari for excellent technical assistance. We would like to thank Dr Sheldon J. Segal, Director, 
Biomedical Division of the Population Council, New York, for suggestions during the course of the investigation. Help received from the Indian Council of Medical Research towards the latter part of the work is gratefully acknowledged.

\section{REFERENCES}

Bengtsson, L. P. \& MoAwad, A. H. (1966) Lippes' loop and myometrial activity. Lancet, i, 146.

BoNNEy, W. A., Jr. \& Cooper, G. (1964) Evaluation of the intra-uterine contraceptive device in a group of 50 women. Proc. 2nd int. Conf. on Intra-uterine Contraception, N.Y. Excerpla med. 86, 221.

Buch, N. C., ShukLA, K. P. \& HAwx, H. W. (1964) Interference with ovulation by intra-uterine plastic devices in Indian water buffaloes. Proc. 5th int. Cong. on Animal Reproduction, Trento, 2, 242.

Chaudhury, R. R. (1964) Effect of intra-uterine silk thread suture on the fertility of female rats. Proc. 2nd int. Conf. on Intra-uterine Contraception, N.Y. Excerpta med. 86, 239.

Chaudiury, R. R. \& Tarak, T. K. (1965) Effect of an intra-uterine silk thread suture on the fertility of female rats. Br. med. F. i, 31 .

Doyle, L. L. \& Margolis, A. J. (1963) Intra-uterine foreign body effect on pregnancy of rats. Science, N.Y. 139, 833.

Doyle, L. L. \& MARgolis, A. J. (1964) Intra-uterine foreign body studies in rodents. Proc. 2nd int. Conf. on Intra-uterine Contraception, N.Y. Excerpta med. 86, 185.

Doyle, L. L. \& MARGolis, A. J. (1966) The effect of an intra-uterine foreign body on reproduction in mice. F. Reprod. Fert. 11, 27.

Ginther, O. J., Woody, C. O., Janakiraman, K. \& Casida, L. E. (1966) Effect of an intra-uterine plastic coil on the oestrous cycle of the heifer. F. Reprod. Fert. 12, 193.

Greenwald, G. S. (1965) Interruption of pregnancy in rat by uterine suture. F. Reprod. Fert. 9, 9.

Hall, H. H., SEDlis, A. \& Chabon, I. (1964) Effect of intra-uterine steel ring on endometrial structure and function. Am. F. Obstet. Gynec. 93, 1031.

Hawk, H. W. (1965) Inhibition of ovum fertilization in the ova by intra-uterine plastic spirals. $\mathcal{J}$. Reprod. Fert. 10, 267.

Hawk, H. W., Conley, H., Brinsfield, T. H. \& Righter, H. F. (1964) Contraceptive effect of plastic devices in cattle uteri. Proc. 2nd int. Conf. on Intra-uterine Contraception, N.Y. Excerpta med. 86, 189.

Israes, R. \& Davis, H. J. (1966) Effect of an IUD on the endometrium. F. Am. med. Ass. 195, 764.

Jessen, D. A., LANE, R. E. \& GreEN, R. R. (1963) Intra-uterine foreign body. A clinical and histopathologic study on the use of the Grafenberg ring. Am. 7. Obstet. Gynec. 85, 1023.

Johnson, W. L., Ek, T. W. \& BREWER, L. L. (1966) Motility of the human uterus before and after insertion of an IUD. Obstet. Gynec., N.Y. 28, 526.

KAR, A. B. (1964) Experimental studies on intra-uterine contraception. Proc. 2nd int. Conf. on Intra-uterine Contraception, N.Y. Excerpta med. 86, 240.

Kar, A. B., Kamboj, V. P., Goswam, A. \& Chowdhury, S. R. (1965) Effect of an intra-uterine contraceptive suture on the uterus and fertility of rats. F. Reprod. Fert. 9, 317.

KeLLY, W. A. \& Marston, J. H. (1967) Contraceptive action of intra-uterine device in the rhesus monkey. Nature, Lond. 214, 735.

KREHBIEL, R. H. (1946) Distribution of ova in the combined uteri of unilaterally ovariectomized rats. Anat. Rec. 96, 323.

Ledger, W. J., Virkar, K. D. \& Irvin, L. A. (1966) Effect of plastic IUCD upon implantation in the rabbit. Obstet. Gynec., N.Y. 28, 521.

LIPPEs, J. (1962) A study of intra-uterine contraception: development of a plastic loop. Proc. 1st int. Conf. on Intra-uterine Contraception, N.Y. Excerpta med. 54, 69.

Malkani, P. K. \& Sujan, S. (1964) Sperm migration in the female reproductive tract in the presence of an IUCD. Am. F. Obstet. Gynec. 88, 963.

Marcus, S. L., Marcus, G. C. \& Wilson, K. H. (1966) Effect of an intra-uterine device on uterine motility in the rat. Obstet. Gynec., N.Y. 27, 238.

Margulies, L. C. (1962) Permanent reversible contraception with an intra-uterine plastic spiral (Perma-spiral). Proc. 1st int. Conf. on Intra-uterine Contraception, N.Y. Excerpta med. 54, 61.

Marston, J. H. \& Chang, M. C. (1964) Experiments on the action of intra-uterine foreign bodies in the rat. Proc. 2nd int. Conf. on Intra-uterine Contraception, N.Y. Excerpta med. 86, 242.

Mastroianni, L., Jr. \& Hongsanand, C. (1964) Mechanism of action of the intra-uterine contraceptive device in the primate. Proc. 2nd int. Conf. on Intra-uterine Contraception, N.Y. Excerpta med. 86, 194. 
Mathur, V. S. \& Chaudhury, R. R. (1968) Effect of an intra-uterine device on the mast cells in the rat uterus. F. Reprod. Fert. 15, 135.

Morese, K. N., Peterson, W. F. \& Allen, S. T. (1966) Endometrial effects of an intra-uterine device. Obstet. Gynec., N.X. 28, 323.

Rozin, S., SACKs, M. I. \& ShENXER, J. G. (1967) Endometrial histology and clinical symptoms following prolonged retention of uterine contraceptive devices. Am. 7. Obstet. Gynec. 97, 197.

Sudha, S., Chakravarty, R. N. \& Chaudhury, R. R. (1967) Effect of an intra-uterine device in rats. Ind. F. med. Res. 55, 1015.

SUJAN, S. \& VIRICK, R. K. (1964) Uterine histopathology in the presence of intra-uterine devices. Proc. 2nd int. Conf. on Intra-uterine Contraception, N.Y. Excerpta med. 86, 172.

TIETzE, C. (1962) Intra-uterine contraceptive rings: history and statistical appraisal. Proc. 1st int. Conf. on Intra-uterine Contraception, N.Y. Excerpta med. 54, 9.

W.H.O. (1966) Technical Report No. 332. 